This is an Author's Accepted Manuscript of an article published in DRYING TECHNOLOGY, 04 Mar 2020, (C) 2020 Taylor \& Francis Group, LLC, available online at: http://www.tandfonline.com/ DOI: 10.1080/07373937.2020.1734608 (c) (i) ()ㅇ (c) (1) () 


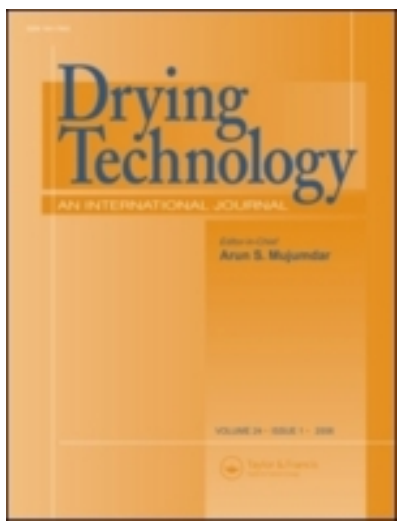

\section{Influence of load mass and drum speed on fabric motion and performance of a heat pump tumble dryer}

\begin{tabular}{|r|l|}
\hline Journal: & Drying Technology \\
\hline Manuscript ID & LDRT-2019-0528.R2 \\
\hline Danuscript Type: & General Paper \\
\hline Author: & 18 -Jan-2020 \\
\hline Complete List of Authors: & $\begin{array}{l}\text { Novak, Lovrenc; University of Ljubljana Faculty of Mechanical } \\
\text { Engineering } \\
\text { Širok, Brane; University of Ljubljana Faculty of Mechanical Engineering } \\
\text { Hočevar, Marko; University of Ljubljana Faculty of Mechanical } \\
\text { Engineering } \\
\text { Gatarić, Pero; Gorenje d.o.o. }\end{array}$ \\
\hline Keywords: & $\begin{array}{l}\text { heat pump tumble dryer, fabric motion, Heat and mass transfer, } \\
\text { regression analysis, energy efficiency }\end{array}$ \\
\hline
\end{tabular}

\section{SCHOLARONE \\ Manuscripts}

This is an Author's Accepted Manuscript of an article published in DRYING TECHNOLOGY, 04 Mar 2020, (c) 2020 Taylor \& Francis Group, LLC, available online at: http://www.tandfonline.com/ DOI: 10.1080/07373937.2020.1734608 


\section{Influence of load mass and drum speed on fabric motion and performance} of a heat pump tumble dryer

Lovrenc Novak $^{\mathrm{a}^{*}}$, Brane Širok ${ }^{\mathrm{a}}$, Marko Hočevar ${ }^{\mathrm{a}}$, Pero Gatarić ${ }^{\mathrm{b}}$

${ }^{a}$ University of Ljubljana, Faculty of Mechanical Engineering, Ljubljana, Slovenia; ${ }^{b}$ Gorenje d.o.o., Velenje, Slovenia

*lovrenc.novak@fs.uni-lj.si 


\title{
Influence of load mass and drum speed on fabric motion and performance of a heat pump tumble dryer
}

\begin{abstract}
The present study investigates fabric motion in the drum and its effect on performance parameters of a domestic heat pump tumble dryer in several operating points, defined by different load masses and drum speeds. Fabric motion in the drum was recorded by using a high-speed camera and evaluated statistically in order to determine the relation between the fabric distribution and the dryer performance parameters. Multiple regression analysis was performed to develop models for condensate mass flow rate as a function of drum speed, load mass and drying stage. The results enable optimization of dryer operating parameters with respect to energy efficiency, drying time per kilogram of fabric and condensate mass flow rate.
\end{abstract}

Keywords: heat pump tumble dryer, fabric motion, heat and mass transfer, regression analysis, energy efficiency

\section{Introduction}

The use of tumble dryers is increasing in modern households since they provide a fast and convenient way of drying clothes. Conventional tumble dryers consume large amounts of electrical energy and are considered as energy-inefficient household appliances. Significant decrease in energy consumption, up to $50 \%$ compared to conventional tumble dryers [1], is achieved by integrating a heat pump into a closed-cycle tumble dryer. Higher energy efficiency and associated smaller contribution to greenhouse gas emissions make heat pump tumble dryers increasingly popular. In the EU, more than $50 \%$ of sold tumble dryers in 2015 were heat pump powered [1]. Besides energy efficiency, other performance parameters such as drying time, noise and load capacity are also important for consumers, therefore further understanding and optimization of processes in tumble dryers is of great interest.

Fabric drying in tumble dryers is a complex combination of heat and mass transfer processes that involves three fluids: water, air and refrigerant. Refrigerant is used in the heat pump cycle for heating and cooling or dehumidifying the drying air, which is circulated 
through the drum to extract moisture from the fabric. The benefits of including a heat pump to the dryer have been first calculated by Braun et al. [2]. Heat pump tumble dryers were later studied by several researchers in order to optimize the process or to include novel concepts. Pal and Khan [3] built mathematical models to design different components of a heat pumpassisted dryer using heat and mass balance of refrigerant and air circuit. Bengtsson et al. [4] modelled and measured the effects of different heat pump compressor sizes on the dryer energy performance. The results showed that increasing the cylinder volume of the compressor by $50 \%$ decreases the drying time by $14 \%$ without using more electricity. Erdem and Heperkan [5] and Mancini et al. [6] investigated effects of using $\mathrm{CO}_{2}$ as a refrigerant in a heat pump dryer. Tests performed on a prototype showed negligible decrease in the electric power consumption and a 9\% increase in the cycle time, compared with the reference R134a heat pump dryer [6]. Ganjehsarabi et al. [7] conducted an exergoeconomic analysis of a heat pump dryer to investigate the system performance and components costs, depending on the operating temperature and mass flow rate of the air. Stawreberg and Wikström [8] measured the energy efficiency of three tumble dryers, two condensing and one heat pump, with different load masses. The results indicated that all tested dryers have significantly lower energy efficiency when drying small loads. Lee et al. [9] presented a heat pump dryer model that accounts for transient effects on both air and refrigerant side. They conducted a parametric study of relevant parameters and concluded that increasing the air flow rate results in higher COP values and shorter drying times. Gatarić et al. [10] studied heat pump tumble dryer performance at different drum speeds, load masses and fan speeds by conducting experiments and developing models by regression analysis. The results showed that larger load masses and higher drum speeds improve the energy efficiency of the drying process, while the opposite effect was attained by increasing the fan speed, which was attributed to lower drying air potential and higher electrical consumption. Junior et al. [11] introduced a 
new concept of a recuperative thermoelectric cycle for a tumble dryer as an alternative to substitute the compression heat pump. Thermoelectric heat pump tumble dryer was modelled and experimentally evaluated also by Patel et al. [12]. TeGrotenhuis et al. [13] computed performance of a hybrid heat pump dryer, where a typical vented dryer was equipped with a heat pump and a recuperative heat exchanger. They demonstrated feasibility of achieving $50 \%$ energy savings with comparable drying times compared to vented tumble dryers.

Conventional tumble dryers, either vented or condensing type, have been studied widely in the open literature. Many researchers have demonstrated positive effects of increasing drying air temperature and flow rate on the tumble dryer performance [14-21]. They also agreed that larger load mass results in higher energy efficiency and shorter drying time per unit mass of clothes [10, 14, 16-18, 22]. Furthermore, Wei et al. [20] have demonstrated improved dryer performance by optimizing the dryer operating parameters for each drying stage. Both drum speed and load mass are key factors that affect fabric motion and consequently the size of contact area between the fabric and the drying air [18]. In order to investigate the interaction effects between these two parameters, the drum speed influence has to be studied in combination with different load masses. This applies to both conventional and heat pump tumble dryers, since drum design and operation and consequently fabric motion are essentially the same for both dryer types. However, even though fabric motion patterns are directly comparable for similar drum designs, the rate of heat and mass transfer processes typically depends on the dryer type. This is attributed to differences in inlet air parameters such as temperature and relative humidity, which are generally less favorable (with respect to drying rates) in case of heat pump tumble dryers.

Experimental studies of fabric movement in a rotating drum are reported in some cases of washing machine research [23-27], but rarely in case of tumble dryer research. Recently Wei et al. [28] conducted measurements with different fabric types and sizes, drying loads 
and drum speeds to determine fabric movement patterns and their effect on the performance of a vented tumble dryer. Fabric movement was analyzed by tracking the outlines of a single fabric item within each drying load using a high-speed camera. The results showed that increasing fabric size and drying load changes fabric movement patterns from only sliding action to more complex movement, involving falling, swing and rotating, which increased moving distance of fabric along the drum. Increasing the drum rotating speed enhanced the centrifugal force, which decreased the frequency of sliding movement and increased the frequency of falling and rotating movement. However, the drum rotating speed of 45-50 rpm was found to be an optimum speed with respect to energy consumption and drying time. They concluded that the complex movement patterns, involving successively sliding, falling, swing and rotating result in higher drying efficiency than repeated single movement due to continuous change of fabric movement and its position, which increases effective heat and moisture transfer area between the fabric and the drying air. Similar experimental approach, which involved tracking a dyed tracer fabric as it was tumbled amongst other fabrics under different drying conditions (fabric size, load mass and initial moisture content), was recently reported by Yu et al [29]. Based on the distribution of fabric velocity profiles, residence time and shear rate they concluded that fabric movement is greatly dependent on the fabric size and drying load size but has no relation to initial moisture content. They defined two most significant fabric motion regions, the bulk region and the disperse region. The size of the disperse region, where fabrics are projected into the air by the rotational motion of the drum, was identified as crucial for the drying process, because it expands the contact area between the fabric and the surrounding air and contributes positively to the heat and mass transfer and to the prevention of wrinkling.

Existing studies on tumble dryers typically treat load mass and drum speed separately in order to assess their effects on integral performance parameters such as energy 
consumption and drying time. These effects are rarely analyzed with respect to time or drying stage. Most studies involve conventional tumble dryers with modified open-air circuits. In contrast, the present study is focused on examination of processes in a typical commercial heat pump tumble dryer, where only modification was to de-couple fan speed from the drum speed by installing an additional electric motor. In this way, characteristics of closed-air circuit and heat pump system remained the same as in the existing appliance. Furthermore, the performance analysis was performed with respect to time, with the aim of providing relations for optimization of dryer operating parameters for different drying stages. Combined effects of load mass and drum speed were examined and interpreted by analyzing fabric motion in the rotating drum. So far, only two comprehensive studies $[28,29]$ have been reported in the open literature, where fabric motion is investigated, based on tracing a single fabric item within a load of similar items. However, the present study represents methods for observation of entire load, composed of different fabric items and size, which seems to be more representative of actual drying loads.

The heat pump tumble dryers have reached a high level of technological advancement, with clearly superior performance compared to conventional tumble dryers, especially with regard to energy efficiency. However, reviewed research demonstrates that further improvements are possible and feasible, not only with respect to energy efficiency, but also to drying time, drying evenness and fabric wrinkling. Accordingly, the aim of this study is to contribute to development of a self-adaptive heat pump tumble dryer that adjusts its operation to load mass and condition of fabric in order to further reduce its energy consumption, drying time and improve other performance parameters. 


\section{Materials and methods}

\section{Experimental setup}

The experimental setup is built using a domestic heat pump tumble dryer with $8 \mathrm{~kg}$ of rated capacity as shown in Figure 1. A typical tumble dryer has a single electric motor that drives both a centrifugal fan and a drum at constant rotating frequency. In this study, an additional BLDC electric motor of the same type was used to drive centrifugal fan separately in order to investigate the influence of drum speed on the fabric motion inside the drum, which measured $570 \mathrm{~mm}$ in diameter and $465 \mathrm{~mm}$ in length. To record fabric movement patterns during the drying cycle, an existing design of glass trap front door was mounted on the dryer, which means that flow and pressure conditions within the closed-air circuit were not modified compared to the commercial appliance. The rotational speed of the centrifugal fan that propels the drying air inside the closed circuit was held constant during the experiment at $2900 \mathrm{rpm}$. The air duct was equipped with several light-emitting diodes, connected in two series as shown in Figure 1, with an adjustable power supply to provide light sufficiently inside the drum. The drum inner surface was entirely painted black to prevent light reflection. With the purpose of measuring the condensate mass with respect to time, a hose was attached to the housing of drain pump, which had been previously removed. The condensate flew directly into a container, which was placed on a weighing scale below the dryer. An axial fan located in front of the compressor was turned off in order to eliminate cooling effects on the heat pump performance. The heat pump with a capillary tube was powered by a single-phase induction motor of the compressor, therefore its operating conditions could not be controlled or maintained constant during the drying cycle. The heat pump operation was not modified and representative of the conditions, present in the commercial dryer model.

The setup employed sensors for temperature, relative humidity, electric power and mass measurement as presented schematically in Figure 2. Two type T thermocouples, with 
an accuracy of $\pm 0.5^{\circ} \mathrm{C}$, were used to measure the drum inlet (T1) and outlet air temperature ( T2). The air relative humidity at the drum inlet $(R H 1)$ and outlet $(R H 2)$ were measured with capacitive humidity transmitters HD9817T1R (Delta Ohm, Italy), with an accuracy of $\pm 2.5 \%$ within the measuring range from $0 \%$ to $100 \%$. The electrical currents of compressor (I1), internal (I2) and external electric motor (I3) were measured using current clamps PNACLAMP-5 (Dewetron, Austria), with an input range from $0.04 \mathrm{~A}$ to $6 \mathrm{~A}$ and accuracy of \pm $0.5 \%$. The electrical power was calculated by a software power module, which provides power measurement and analysis. Integration of electrical power was used to determine the energy consumption. All measured variables were recorded with a 16-slot chassis DEWE-800 (Dewetron) data acquisition system and sampled every second. Two scales FCB 30K1 (Kern, Germany), with a resolution of $1 \mathrm{~g}$ and accuracy of $\pm 3 \mathrm{~g}$ were used for weighing clothes before and after each test and measuring the condensate mass. Drum speed settings were checked with a contact tachometer DT-2268 (Lutron, Taiwan), with a resolution of $1 \mathrm{rpm}$ and accuracy of $\pm 0.05 \%$. A digital high-speed camera HiSpec 4 (Fastec, USA), with a resolution of 1696 x 1710 at up to 500 frames per second, was used to record fabric motion inside the rotating drum. Images were recorded every $200 \mathrm{~g}$ of accumulated condensate at each load mass for a time interval of one drum revolution.

\section{Experimental procedure}

The drying experiment was carried out in an environmentally controlled chamber in accordance with the standard requirements. The temperature and relative humidity were maintained at $23{ }^{\circ} \mathrm{C} \pm 2{ }^{\circ} \mathrm{C}$ and $55 \% \pm 5 \%$, respectively. The voltage regulator ensured constant supply voltage of $230 \mathrm{~V} \pm 2 \%$ and frequency of $50 \mathrm{~Hz} \pm 1 \%$ [30]. Three different drying loads of long staple pure cotton [31] were tested: 2, 4 and $6 \mathrm{~kg}$. Each load was composed of a certain number of sheets, pillowcases and towels as shown in Table 1. In order 
to assess the evenness of drying (not discussed in this paper), the iron dry cotton program was selected for all test runs. Accordingly, the tolerance of the final moisture content of $12 \%$ was reduced from $\pm 4 \%$ to $\pm 2 \%[30]$. The textiles were wetted homogenously in a washing machine to a moisture content of $60 \% \pm 1 \%$ and inserted into drum piece by piece according to the internal procedure to reduce the variation in results. The drying cycle ends automatically when the textiles reach the desired moisture content, detected by a humidity sensor in the drum. The energy consumption $E(\mathrm{Wh})$ and drying time $t(\mathrm{~min})$ were corrected for the actual initial and final moisture content in the textiles and calculated as:

$$
\begin{gathered}
E=\frac{E_{m}\left(\mu_{i 0}-\mu_{f 0}\right) c}{W_{i}-W_{f}} \\
t=\frac{t_{m}\left(\mu_{i 0}-\mu_{f 0}\right) c}{W_{i}-W_{f}}
\end{gathered}
$$

where $E_{m}(\mathrm{Wh})$ and $t_{m}(\mathrm{~min})$ are measured energy consumption and drying time, $\mu_{i 0}$ is the nominal initial moisture content, $\mu_{f 0}$ is the target final moisture content, $W_{i}(\mathrm{~kg})$ is the weight of the textiles after wetting, $W_{f}(\mathrm{~kg})$ is the weight of the textiles after drying and $c(\mathrm{~kg})$ is the load mass [30]. The corrected energy consumption and drying time (Eqs. 1 and 2) were later divided by load mass to define the energy efficiency and drying time per kilogram of load. The combined measurement uncertainty of the energy efficiency was determined according to [32] and is presented in Figure 7.

\section{Regression analysis}

The regression analysis was used to model the relationship between various response and 
independent variables. At first, models were developed to relate the corrected measured energy consumption $E(\mathrm{Wh})$ and drying time $t(\mathrm{~min})$ to drum speed $n(\mathrm{rpm})$ and load mass $c$ (kg). Here, simple polynomial regression was used to fit either linear or quadratic curves to the measured points. The quadratic model is in this case defined as:

$$
y=\beta_{0}+\beta_{1} n+\beta_{2} n^{2}+\varepsilon
$$

where $y$ is a response variable, $\beta$ 's are unknown regression coefficients and $\varepsilon$ is a statistical error, which represents the difference between the measured and the exact value of $y$ [33]. The regression coefficients were estimated using a method of least squares, which minimizes the sum of squared errors. Each process variable was considered at three values, low, intermediate and high (load mass of 2, 4 and $6 \mathrm{~kg}$ and drum speed of 36, 47 and $58 \mathrm{rpm}$ ). The combination of these values resulted in a total number of 9 operating points.

Further regression analysis was used to relate condensate mass flow rate $m_{c}(\mathrm{~g} / \mathrm{min})$ to drum speed, load mass and an additional variable to account for the relative drying time. Several definitions of the relative drying time were tested in the analysis and finally the relative condensate mass $m_{c, r e l}(\%)$ was chosen as it provided the best fit to the measured data:

$$
m_{c, r e l}=\frac{m_{c}(t)}{m_{c}\left(t_{\text {end }}\right)}
$$

where $m_{c}$ is the condensate mass, accumulated in the container, $t$ is the current time and $t_{\text {end }}$ is the total drying time. Condensate mass flow rates were calculated from measured data for intervals of $100 \mathrm{~g}$ of accumulated condensate, that is by dividing $100 \mathrm{~g}$ by the respective time, 
needed for accumulation of such condensate mass:

$$
\dot{m}_{c}=\frac{m_{c}\left(t_{m}\right)-m_{c}\left(t_{m-100}\right)}{t_{m}-t_{m-100}}=\frac{100 \mathrm{~g}}{t_{m}-t_{m-100}}
$$

where $t_{m}$ is time for accumulation of current mass of condensate (evaluated at $100 \mathrm{~g}$ intervals) and $t_{m-100}$ is time for accumulation of previous mass (100 g less) of condensate. For example, mass flow at $500 \mathrm{~g}$ condensate was calculated as $100 \mathrm{~g}$ divided by difference of current time and time at $400 \mathrm{~g}$ accumulated condensate.

Regression models for the condensate mass flow rate were developed in three stages:

(1) First, models were developed separately for each load mass and condensate mass, which means that the condensate mass flow rate was modeled only as a function of drum speed. The purpose of this stage was to determine effect of drum speed for each load mass and to investigate how regression coefficients change with time. At 4 and 6 $\mathrm{kg}$ loads, a linear model (Eq. 6) provided a good fit to measured data, whereas at $2 \mathrm{~kg}$ load it was necessary to include the quadratic term (Eq. 7).

$$
\begin{gathered}
\dot{m}_{c}=\beta_{0}+\beta_{1} n \\
(6) \\
\dot{m}_{c, 2}=\beta_{0,2}+\beta_{1,2} n+\beta_{2,2} n^{2}
\end{gathered}
$$

(2) In the second stage, regression coefficients were modeled as functions of relative condensate mass $\left(m_{c, r e l}\right)$. Analysis of data from the first stage of modeling showed 
similar trends for 4 and $6 \mathrm{~kg}$ loads, therefore a common model could be developed, whereas the $2 \mathrm{~kg}$ load had to be modeled separately. Regression analysis was performed in MS Excel by using the GRC nonlinear solver to minimize the sum of squared errors. Several models were tested and evaluated by comparing the sum of squared errors and coefficient of determination $\left(R^{2}\right)$. For 4 and $6 \mathrm{~kg}$ loads, the best model fit was obtained when intercept term $\beta_{0}$ was set as quadratic function of the $m_{c, r e l}$, coefficient $\beta_{1}$ as linear function of the $m_{c, r e l}$ and coefficient $\beta_{2}$, which is multiplied by load mass, as a constant. For the $2 \mathrm{~kg}$ load, the free coefficient $\beta_{0,2}$ was also set as quadratic function of the $m_{c, \text { rel }}$, while both $\beta_{1,2}$ and $\beta_{2,2}$ were set as linear functions of the $m_{c, r e l}$.

(3) The final stage involved statistical tools for verification of developed models. The stepwise regression method in Matlab [34] was employed to fit linear models to the same data as in previous stages. The stepwise regression algorithm starts from the initial model and then adds or removes predictors from the model by evaluating a chosen statistical criterion. In this case, the criterion was always based on $p$-value for an $F$-test [33] of the change in the sum of squared error that results from adding or removing the term. The threshold $p$-value for inclusion and removal of the term was set at 0.05 and 0.1 , respectively. Resulting linear models involve three independent variables $\left(m_{c, r e l}, n, c\right)$ that appear in linear, quadratic and interaction terms as represented by Eqs. 8 and 9.

$$
\dot{m}_{c}=\beta_{00}+\beta_{01} m_{c, r e l}+\beta_{10} n+\beta_{20} c+\beta_{02} m_{c, r e l}^{2}+\beta_{11} m_{c, r e l} n+\beta_{30} n^{2}
$$

$$
\dot{m}_{c, 2}=\beta_{00}+\beta_{01} m_{c, r e l}+\beta_{10} n+\beta_{02} m_{c, r e l}^{2}+\beta_{11} m_{c, r e l} n+\beta_{30} n^{2}+\beta_{31} m_{c, r e l} n^{2}
$$


Eqs. 8 and 9 are almost identical to the models that were developed in the previous stage of modeling. The only difference is the square term for drum speed $\left(\beta_{30} n^{2}\right.$, Eq. 8), which was not included in the model from previous stage. Since this term was determined as significant according to the chosen statistical criterion, it was decided to leave it in the final models.

\section{Methodology for processing fabric distribution and motion}

Variation of fabric motion patterns in the observed window was evaluated by introduction of a scalar variable $A(x, y)$ and an integral estimator $\overline{\langle A\rangle}$, given by Eqs. (10) and (11)

$$
A(x, y)=\frac{1}{N} \sum_{t} E(x, y, t) \quad E(x, y, t)=\{0,1,2, \ldots 255\} ;\{x, y\} \in \text { mask }
$$

$$
\overline{\langle A\rangle}=\frac{1}{N} \sum_{t} \sum_{x} \sum_{y} E(x, y, t)
$$

where $E(x, y, t)$ is an integer variable, which represents grayness (brightness) level and depends on space and time. The range of grayscale image brightness levels and corresponding values of $A$ is between 0 and 255. Position of each pixel in the observed window determined by selection of mask over recorded image is represented by integer parameters $(x, y)$. Variable $A(x, y)$ represents time-averaged grayness values within a selected time interval that includes $N$ recorded images. To obtain the spatial and temporal average grayness value $\overline{\langle A\rangle}$ it is necessary to compute the average of $E(x, y, t)$ with respect to the chosen observation time and space (Eq. 
11). Here, $N$ represents number of included values of $E(x, y, t)$. By presuming that the value of $A(x, y)$ is a proportional estimator of fabric presence (or concentration distribution) at given space and time (Eq. 12), a quantitative assessment of fabric topology can be performed for the observed window within the chosen time interval [35-37]. In summary, if $A(x, y)$ represents time-averaged fabric concentration in form of $2 \mathrm{D}$ distributions, then $\overline{\langle A\rangle}$ represents $1 \mathrm{D}$ data and indicates average fabric concentration for selected space and time intervals.

$$
A(x, y) \propto \rho(x, y)
$$

Estimation of fabric kinematics and consequently fabric deformation was performed by applying the advection method, which enables determination of velocity fields of variable $A$ inside the observed window. For this purpose, the ADM-flow method $[38,39]$ was employed, which computes velocity field $\left(v_{x}, v_{y}\right)$ in a chosen time interval $t$ by solving Eq. (13) using the finite element method.

$$
\frac{\partial A}{\partial t}=\frac{\partial\left(v_{x} A\right)}{\partial x}+\frac{\partial\left(v_{y} A\right)}{\partial y}
$$

\section{RESULTS AND DISCUSSION}

\section{Fabric distribution and motion}

Fabric distribution in a rotating drum depends on the drum size, surfaces and speed, load mass, interaction between individual load pieces, lifter shapes and gravity. Fabric distribution and motion was examined by estimating instantaneous velocity fields of fabric surfaces in the observed window using the ADM-flow code [38,39] and by computing the simultaneous local 
fabric concentration in Matlab [34]. Results were obtained in form of images as presented in Figure 3. Recorded fabric motion was analyzed for all operating points and different drying stages, defined by the relative condensate mass. However, the velocity fields served only as a supplementary tool for interpretation of fabric dynamics and were not further related to any performance parameters, therefore only one example is presented. Figure 3 displays a typical local velocity distribution (a) and corresponding local fabric concentration (b) for the time interval of 10 sequential images, that were selected arbitrarily from a set of recorded images. The observation range of the drum as shown in Figure 3a was limited by the existing glass front door and lint filter design. In addition, the edge section of the observed window was eliminated from the analysis due to light refraction, therefore the observed cross-section area represented approximately $60 \%$ of the total front opening area. Despite the limited size of the observed window, its position enabled observation of the most significant fabric movement patterns, including lifting, rotating and falling of fabrics. Fabric motion at the drum bottom and perimeter, where fabric usually slides over the lifters or rotates, attached to the drum wall, could not be entirely observed.

Figure 3(a) clearly shows that velocities in the left part of the drum are characteristically smaller than elsewhere, which can be explained by the fabric accumulation in this area. Smaller velocities and longer fabric residence times are reflected in higher local fabric concentration, as evident in Figure 3(b). As fabric is lifted to the upper and central part of the drum its velocity increases due to gravitational force that acts towards the drum bottom and tangential force that acts in direction of the drum rotation, which is indicated in Figure $3 \mathrm{a}$ by direction of velocity field. Examination of fabric distribution shows that the area of high concentration in the left part of the drum transitions to the area of smaller concentration, which allows expansion of fabric and its free fall towards the bottom in the right part of the drum. Significantly higher velocities, oriented in direction of the drum rotation, corresponding 
also to direction of the gravity vector, are present in the right part of the drum. Fabric concentration in this part is very low for the presented operating point $(2 \mathrm{~kg}$ load, $36 \mathrm{rpm}$ drum speed and 400g condensate mass). Moreover, areas without any fabric are visible close to the drum wall in the right part of the drum, which means that open-flow path for air is formed, which reduces the contact area and decreases the moisture transport rate between the fabric and the drying air.

Figure 4 presents air relative humidity at the drum outlet, condensate mass (condensed water from the heat pump, Figure 2) and time-averaged fabric concentration $(A)$ for 2 operating points at constant drum speed of $36 \mathrm{rpm}$ and different load masses ( 2 and $4 \mathrm{~kg}$ ). The time interval for computation of each average fabric concentration corresponded to one drum revolution. The relative humidity and condensate mass curves demonstrate higher saturation of outlet drying air and faster accumulation of condensate at higher load masses. Higher drying rates at higher loads are expected and can be interpreted by investigation of the fabric concentration during the drying process. In Figure 4, fabric concentration images were selected at conditions of approximately $30 \%, 60 \%$ and $90 \%$ relative condensate mass, which define the observed drying stages. At higher loads, distributions of $A$ are generally more uniform and stable, which reflects higher and more homogenous presence of fabric across the observed window for all observed drying stages. At smaller loads, variability of $A$ is higher in both space and time. For example, at $200 \mathrm{~g}$ condensate mass, accumulation of fabric is visible in the lower left part of the drum through locally increased values of $A$. As fabric is lifted due to the drum rotation, the local concentration is increasing, reaches an extreme and then transitions to lower values due to fabric expansion and acceleration towards the drum bottom. The low fabric concentration in the right part of the window increases airflow through this part of the drum and consequently decreases the contact area between the air and the fabric. As drying process progresses to $600 \mathrm{~g}$ condensate mass, the fabric distribution in the drum 
becomes more uniform. Consequently, distribution of $A$ across the entire window becomes relatively homogenous in the final observed drying stage. This indicates that the fabric redistributes and expands to occupy a larger drum volume, which reduces formation of openflow paths between the fabrics. These conditions are favorable for increasing moisture transfer rate from the fabric to the drying air and consequently for reducing the drying time.

Accumulation of condensate mass $\left(m_{\mathrm{c}}\right)$, as displayed in Figure 4, was used for selection of time intervals in length of one drum revolution, where typical distributions of $A$ were analyzed at load of $2 \mathrm{~kg}$ and condensate of 200,400 and $600 \mathrm{~g}$. The spatially averaged value of $A$ (also $\overline{\langle A\rangle}$ ) was used in further analysis for formation of functional relation of $\overline{\langle A\rangle}$ ( $m_{c}$ ), which describes influence of fabric distribution on the drying efficiency at the integral level.

Figure 5 displays space- and time-averaged values of $A$, where space limits are represented by the area of observation, as shown in Figure 3, and time interval was selected to include data for one drum revolution. At $2 \mathrm{~kg}$ load, all operating points are displayed, while at $4 \mathrm{~kg}$ and $6 \mathrm{~kg}$ load, only operating points at low and high drum speed are presented. By assuming that $\overline{\langle A\rangle}$ is proportional to fabric distribution in the drum, the presented diagram enables study of significance of integral parameters, including load mass and drum speed with respect to drying time, expressed as relative condensate mass. As evident from the diagram, the $\overline{\langle A\rangle}$ values at $2 \mathrm{~kg}$ load are generally lower than at 4 and $6 \mathrm{~kg}$ loads, however, at $2 \mathrm{~kg}$ load the $\overline{\langle A\rangle}$ is increasing progressively while at 4 and $6 \mathrm{~kg}$ loads the increasing of $\overline{\langle A\rangle}$ is degressive. Considering all the presented cases, it can be concluded that occupation of the drum volume by fabrics increases with time, meaning that open areas with no presence of fabric are reduced. This affects drying on smaller scales through increasing of local air velocities and the contact area between the fabric and air, which improves heat and mass transfer between the two media. 
Figure 6 shows phenomenological relation between the condensate mass flow rate, determined by the developed models (Eq. 8 and 9), and space- and time-averaged fabric concentration, represented by the variable $\overline{\langle A\rangle}$ at three different drying stages, that is at $20 \%$, $50 \%$ and $80 \%$ relative condensate mass. The diagram includes the same data as in case of Figure 5. The points for each drying stage are related by a second order polynomial. Figure 6 indicates that the best fit is obtained at $20 \%$ condensate mass, where $R^{2}=0.9839$. This shows a strong relationship between the fabric concentration and the dryer performance in the first observed drying stage. The relationships at $50 \%$ and $80 \%$ relative condensate mass are very similar, however, the $R^{2}$ drops to 0.9409 and 0.8355 , respectively. Based on the presented analysis it can be concluded that the relation between the observed average fabric concentration $\overline{\langle A\rangle}$ and dryer performance dissipates as the drying progresses. This is most probably caused by expansion of fabric as it gets dry, which reflects in increasing of $\overline{\langle A\rangle}$ and coincident lower correlation of $\overline{\langle A\rangle}$ to the condensate mass flow rate. The reduction of correlation could be resulting from the limitation of the presented method of fabric observation and subsequent averaging but could also indicate decreased significance of fabric distribution and coincident raising significance of other influences, related to fabric motion in the drum.

\section{Energy efficiency and drying time}

Energy efficiency (energy consumption per kilogram of load, $\mathrm{kWh} / \mathrm{kg}$ ) and drying time per kilogram of load $(\mathrm{min} / \mathrm{kg})$ were evaluated for all combinations of the process variables. Each operating point was measured twice, therefore 18 test results were available. One test at $6 \mathrm{~kg}$ load and $58 \mathrm{rpm}$ was later identified as an outlier and rejected. Therefore, 17 tests were considered as valid and appropriate for further analysis. 
Measured energy consumption and drying time per kilogram of load, which were corrected for the actual initial and final moisture content in the fabric (Eqs. 1 and 2), are presented as markers in Figures 7 and 8, respectively. The energy consumption values (Figure 7) are presented with error bars that correspond to the expanded measurement uncertainty ( $95 \%$ confidence interval), determined according to uncertainty propagation laws [32]. For 2, 4 and $6 \mathrm{~kg}$ loads, the highest uncertainties were calculated to be $4.8,3.7$, and $3.3 \mathrm{Wh} / \mathrm{kg}$, respectively. Figures 7 and 8 depict similar trends, which indicates a close relationship between the energy efficiency and the drying time per kilogram of load. The positive effect of a larger load mass on the energy efficiency and drying time per kilogram of load is evident and is in line with conclusions from other studies ([10], [14], [16-18], [22]). Increasing the load mass in a constant drum volume increases the contact area between the fabric and the drying air, which increases the heat and moisture transport [18]. This effect is limited by the ratio of drum volume to load mass, however, results from the present and previous study [10] that also included an $8 \mathrm{~kg}$ load, do not indicate the presence of an optimal load mass. On the other side, if the mass load is too small, the contact between the fabric and the drying air is poor and possibly a significant amount of air is bypassed through voids in the drum, which leads to lower energy efficiency of the drying process.

As evident from Figures 7 and 8, the effect of drum speed on the dryer performance has to be examined in relation to load mass. At $2 \mathrm{~kg}$ load an optimal drum speed is visible at around $47 \mathrm{rpm}$ while at larger loads, the dryer performance increases linearly with the drum speed. Further increasing of drum speed beyond $58 \mathrm{rpm}$ was carried out in order to find the optimal drum speed values at larger mass loads, however it turned out to be very difficult to produce valid tests at these settings. The results from this and previous study, conducted on a similar experimental setup [10], indicate linear influence of drum speed at larger load masses and provide no solid basis that could be used for determination of the optimal drum speed. 
Accordingly, performance parameters at $2 \mathrm{~kg}$ load were fitted with quadratic curves while in case of 4 and $6 \mathrm{~kg}$ loads, they were fitted with lines. Coefficients of determination $\left(R^{2}\right)$ for the respective curves are given on the diagram. Some studies have determined optimal drum speeds also for larger load masses (for example, $45-50 \mathrm{rpm}$ at $5 \mathrm{~kg}$ load in a vented dryer type [28]), but this requires consideration of several factors such as the dryer type, drum size, inlet drying air parameters, fabric type, etc. that vary from study to study.

\section{Models for the condensate mass flow rate}

Condensate mass flow rate is an indicator of the drying rate, which in this case depends on the heat and mass transfer processes in the entire tumble dryer, especially in the drum and heat pump. Since heat pump operation and fan speed were constant during the experiment, it is expected that processes in the rotating drum had the greatest impact on the variation of condensate mass flow rate.

Condensate mass flow rate models were developed by regression analysis of measured data according to the procedure, explained in section 2.3. The measured condensate mass flow rate between 0 and $100 \mathrm{~g}$ accumulated condensate was not considered when developing models, since it was significantly lower than the subsequent mass flow rates. This is due to the warm-up period of the drying process that includes several minutes with zero condensate mass flow from the evaporator.

\section{4 and $6 \mathrm{~kg}$ load}

The regression model for the 4 and $6 \mathrm{~kg}$ load is defined by inserting values of regression coefficients, obtained by the least squares method, into Eq. 8:

$\dot{m}_{c}$

$$
\begin{aligned}
& =0.01596+0.32265 m_{c, r e l}+0.02942 n+0.00602 c-0.36651 m_{c, r e l}^{2}+0.00304 m_{c, r e l} \\
& n-4.92 \times 10^{-5} n^{2}
\end{aligned}
$$


The coefficient of determination $\left(R^{2}\right)$ of the model is 0.953 and the adjusted $R^{2}$ statistic, which decreases if unnecessary terms are added to the model [33], is 0.950. Plot of predicted vs. measured condensate mass flow rate is presented in Figure 9(a). Deviation of points from the line of equality is spread evenly, which indicates that the model is unbiased. There is only a slight increase of residual in the first and final observed drying stage (low and high $m_{c, r e l}$ ), which could indicate either higher experimental or modeling error for these drying stages. Interpretation of the model (Eq. 14) is complicated by the fact that both quadratic and interaction terms are included for two regressors $\left(m_{c, r e l}\right.$ and $\left.n\right)$. However, the load mass $c$ is represented only by a linear term, which makes explanation of its impact easier, namely higher load mass results in higher condensate mass flow rate. The linear effect of load mass is evident also from the dryer performance parameters, shown in Figures 7 and 8 . The effects of drum speed $n$ and drying stage, defined by the relative condensate mass $m_{c, r e l}$, have to be examined together. Figure 10 illustrates computed condensate mass flow rate as a function of both $n$ and $m_{c, r e l}$, according to Eq. 14. Surfaces, corresponding to different load masses, are separated by a constant spacing, defined by the linear load mass term in Eq. 14. The surface curvature with respect to $m_{c, r e l}$ is evident while the curvature with respect to $n$ is less significant. The nonlinear effect of drum speed, represented by the last term in Eq. 14, is weak and possibly a linear relation could be assumed within the investigated range of operating parameters, similar as in the case of dryer energy efficiency and drying time. For similar reasons, determining optimal drum speed by differentiation of Eq. 14 is not justified as it would require significant extrapolation.

\section{$2 \mathrm{~kg}$ load}

Model for prediction of the condensate mass flow rate at $2 \mathrm{~kg}$ load is based on Eq 9. When 
values of regression coefficients are inserted, the model becomes:

$$
\begin{gathered}
\dot{m}_{c, 2}=0.13569-0.5446 m_{c, r e l}+0.00469 n-0.27358 m_{c, \text { rel }}^{2}+0.038934 m_{c, \text { rel }} n-5.72 \\
\times 10^{-5} n^{2}-0.0004 m_{c, r e l} n^{2}
\end{gathered}
$$

The coefficient of determination $\left(R^{2}\right)$ of the model is 0.949 and the adjusted $R^{2}$ is 0.936 . Plot of predicted vs. measured condensate mass flow rate is presented in Figure 9(b). Similar to the model for larger load masses, the deviation of points from the line of equality is spread evenly.

The model includes two regressors and both appear in linear, quadratic and interaction terms. The prediction data are presented by a 3D plot (Figure 11). Compared to the 4 and $6 \mathrm{~kg}$ model, the $2 \mathrm{~kg}$ model shows a significant non-linear response with respect to both drum speed and drying stage. An optimal drum speed for the entire range of $m_{\mathrm{c}, \text { rel }}$ can be determined from the model by differentiation of Eq. 15 relative to $n$ :

$$
\begin{gathered}
\frac{\partial \dot{m}_{c, 2}}{\partial n}=0.00469+0.038934 m_{c, \text { rel }}-1.144 \times 10^{-4} n-0.0008 m_{c, r e l} n=0 \\
(16) \\
n=\frac{0.00469+0.038934 m_{c, \text { rel }}}{1.144 \times 10^{-4}+0.0008 m_{c, \text { rel }}}
\end{gathered}
$$

Plot of Eq. 17 (Figure 12 and thick line on Figure 11) shows that the optimal drum speed is increasing with the accumulation of condensate, however, the increase from $20 \%$ to $90 \%$ relative condensate mass is only $2 \mathrm{rpm}$. The benefit of following the optimal drum speed curve, compared to the operation at constant drum speed of $47 \mathrm{rpm}$ was calculated to be of the 
order of $1 \%$ of the average condensate mass flow rate. Such small benefit in dryer performance, combined with requirements for precise control of drum speed, negates feasibility of drum speed adjustments during drying of small loads. Potential higher benefits could result from drum speed adjustment during the warm-up drying period (before 20\% accumulated condensate), but data for this drying period is not included in the presented model. Since this period requires approximately one third of the total drying time at $2 \mathrm{~kg}$ load, as seen in Figure 4, it has a significant contribution to the dryer performance parameters and was therefore examined separately in more detail. Measured data reveals that duration of the warm-up period and the corresponding condensate mass flow rate depend on drum speed in a similar way, as for the subsequent drying period. Best performance was achieved at $47 \mathrm{rpm}$ drum speed, which is indicated by shortest warm-up period, shortest time to detect the first condensate in the container and on average highest air relative humidity at the drum outlet. At 36 and $58 \mathrm{rpm}$, all the mentioned performance parameters deteriorated to a similar degree.

\section{Conclusions}

A heat pump tumble dryer was investigated to analyze the influence of load mass and drum speed on the dryer performance. Regression analysis was employed to develop models for prediction of the condensate mass flow rate as a function of operating parameters and drying stage, represented by the relative condensate mass. Additionally, fabric motion and distribution in the drum was recorded and statistically evaluated in order to determine the relation between fabric motion dynamics and dryer performance parameters.

Measurements of the total energy consumption and drying time per kilogram of load clearly show a positive influence of higher load masses on both performance parameters. However, the effect of drum speed was found to be dependent on the load mass. For $2 \mathrm{~kg}$ load, the drum speed effect was non-linear and was modeled by a second order polynomial function, which means that an optimal value could be determined at approximately $47 \mathrm{rpm}$. 
For higher load masses ( 4 and $6 \mathrm{~kg}$ ) the effect was linear, therefore no optimum value could be determined within the investigated range of drum speeds. Similar conclusions were drawn on the basis of regression models for the condensate mass flow rate, where effects of drum speed and load mass appear in interaction. In addition, the regression models enable prediction of the heat pump tumble dryer performance as a function of drying stage, expressed as the relative condensate mass. It was determined that variation of condensate mass flow rate with respect to drying time is as significant as its variation due to different drum speeds and that both variables are related to the condensate mass flow rate in a non-linear way.

Presented analysis of fabric motion and distribution leads to the conclusion that the fabric distribution inside a rotating drum has a significant contribution to the heat and mass transfer rates and consequently affects the dryer performance. To improve moisture transfer rate from the fabric to the drying air it is favorable to achieve a homogenous fabric distribution and to reduce local fabric accumulation and formation of areas with no fabric in the drum. Relationship between the space- and time-averaged fabric concentration in the observed window and the modeled dryer performance was found to be strong in the first observed drying stage, where it could be described by a second order polynomial. As the drying progresses to the final observed drying stage the relation weakens, which is reflected in poor regression statistics. This can be explained by expansion of fabric as it gets dry, resulting in increased fabric presence in the observed area, consequently higher values of space- and time-averaged fabric concentration and coincidently lower correlation of averaged fabric concentration to the dryer performance. In summary, the presented study indicates possibilities for further development of self-adaptive heat pump tumble dryers, which are capable of adjusting their operation in order to reach a more homogeneous fabric distribution inside the rotating drum. For this purpose, solutions such as continuous variation of drum rotational speed and direction with respect to load type and mass could be utilized. 


\section{Acknowledgements}

The authors acknowledge the financial support from the Slovenian Research Agency (research core Funding No. P2-0401). The article is in part the result of work in the implementation of the Operation entitled SPS - IQDOM, co-financed by the Republic of Slovenia and the European Union under the European Regional Development Fund (OP20.00376).

\section{References}

[1] Michel, A.; Attali, S.; Bush, E. Energy efficiency of White Goods in Europe: Monitoring the Market with Sales Data - Final Report. ADEME, December 2016.

[2] Braun, J. E.; Bansal, P. K.; Groll, E. A. Energy efficiency analysis of air cycle heat pump dryers. Int. J. Refrig. 2002, 25, 954-965.

[3] Pal U. S.; Khan Md. K. Calculation Steps for the Design of Different Components of Heat Pump Dryers Under Constant Drying Rate Conditions. Drying Technol. 2008, 26, 864-872.

[4] Bengtsson, P.; Berghel, J.; Renström, R. Performance Study of a Closed-Type Heat Pump Tumble Dryer Using a Simulation Model and an Experimental Set-Up. Drying Technol. 2014, 32, 891-901.

[5] Erdem S.; Heperkan H. Numerical Investigation of the Effect of Using CO2 as the Refrigerant in a Heat Pump Tumble Dryer System. Drying Technol. 2014, 32, 1923 1930.

[6] Mancini F.; Minetto S.; Fornasieri E. Thermodynamic Analysis and Experimental Investigation of a CO2 Household Heat Pump Dryer. Int. J. Refrig. 2011, 34, 851-858.

[7] Ganjehsarabi, H.; Dincer, I.; Gungor, A. Exergoeconomic Analysis of a Heat Pump Tumbler Dryer. Drying Technol. 2014, 32, 352-360.

[8] Stawreberg L.; Wikström F. Does the Energy Labelling System for Domestic Tumble Dryers Serve its Purpose?. J. Cleaner Prod. 2011, 19, 1300-1305.

[9] Lee, B.-H.; Sian, R. A.; Wang, C.-C. A Rationally Based Model Applicable for Heat Pump Tumble Dryer. Drying Technol. 2019, 37, 691-706.

[10] Gatarić, P.; Širok, B.; Hočevar, M.; Novak, L. Modeling of Heat Pump Tumble Dryer Energy Consumption and Drying Time. Drying Technol. 2019, 37, 1396-1404.

[11] Junior C.; Chen G.; Koehler J. Modeling of a New Recuperative Thermoelectric Cycle for a Tumble Dryer. Int. J. Heat Mass Transf. 2012, 55, 1536-1543. 
[12] Patel, V. K.; Gluesenkamp, K. R.; Goodman, D.; Gehl, A. Experimental Evaluation and Thermodynamic System Modeling of Thermoelectric Heat Pump Clothes Dryer. Appl. Energy 2018, 217, 221-232.

[13] TeGrotenhuis, W.; Butterfield, A.; Caldwell, D.; Crook, A.; Winkelman, A. Modeling and Design of a High Efficiency Hybrid Heat Pump Clothes Dryer. Appl. Therm. Eng. 2017, 124, 170-177.

[14] Deans, J. The Modelling of a Domestic Tumbler Dryer. Appl. Therm. Eng. 2001, 21, 977-990.

[15] Do, Y.; Kim, M.; Kim. T.; Jeong, S.; Park, S.; Woo, S.; Kwon, Y.; Jung, Y.; Lee, J.; Ahn, Y. An Experimental Study on the Performance of a Condensing Tumbler Dryer with an Air-to-air Heat Exchanger. Korean J. Chem. Eng. 2013, 30, 1195-1200.

[16] Yadav, V.; Moon, C. G. Fabric-drying Process in Domestic Dryers. Appl. Energy 2008, $85,143-158$.

[17] Bassily, A. M.; Colver, G. M. Performance Analysis of an Electric Clothes Dryer. Drying Technol. 2003, 21, 499-524.

[18] Bassily, A. M.; Colver, G. M. Correlation of the Area-Mass Transfer Coefficient Inside the Drum of a Clothes Dryer. Drying Technol. 2003, 21, 919-944.

[19] Stawreberg, L.; Nilsson, L. Modelling of Specific Moisture Extraction Rate and Leakage Ratio in a Condensing Tumble Dryer. Appl. Therm. Eng. 2010, 30, 2173-2179.

[20] Wei, Y.; Gong, R. H.; Ning, L.; Ding, X. Enhancing the Energy Efficiency of Domestic Dryer by Drying Process Optimization. Drying Technol. 2018, 36, 790-803.

[21] Novak, L.; Gatarić, P.; Širok, B. Influence of Drum Inlet Air Conditions on Drying Process in a Domestic Tumble Dryer. Drying Technol. 2019, 37, 781-792.

[22] Stawreberg, L.; Nilsson, L. Potential Energy Savings Made by Using a Specific Control Strategy when Tumble Drying Small Loads. Appl. Energy 2013, 102, 484-491.

[23] Mac Namara, C.; Gabriele, A.; Amador, C.; Bakalis, S. Dynamics of Textile Motion in a Front-loading Domestic Washing Machine. Chem. Eng. Sci. 2012, 75, 14-27.

[24] Park, S.; Yun, C.; Kim, J.; Park, C. H. The Effects of the Fabric Properties on Fabric Movement and the Prediction of the Fabric Movements in a Front-loading Washer. Text. Res. J. 2013, 83, 1201-1212.

[25] Yun, C.; Park, C. H. The Effect of Fabric Movement on Washing Performance in a Front-loading Washer II: Under Various Physical Washing Conditions. Text. Res. J. 2015, 85, 251-261. 
[26] Yun, C.; Park, C. H. The Effect of Fabric Movement on Washing Performance in a Front-loading Washer III: Focus on the Optimized Movement Algorithm. Text. Res. J. 2016, 86, 563-572.

[27] Liu, H.; Wang, Y.; Gong, R. H.; Zeng, J.; Ding, X. The Relationships Between Washing Parameters, Fabric Movement, and Wrinkling in a Top-loading Washer. Text. Res. J. 2018, 88, 1367-1376.

[28] Wei, Y.; Su, Z.; Zhang, Y.; Li, P.; Yuan, H. The Effect of Fabric Movement on Drying Performance of the Domestic Drum Dryer. J Text. I. 2019, 110, 1059-1071.

[29] Yu, X.; Ding, X. The Transverse Motion of Fabrics in Domestic Tumble Dryers Under Different Drying Conditions, Drying Technol. 2019, DOI: 10.1080/07373937.2019.1693398

[30] IEC 61121. Tumble dryers for household use - Methods for measuring the performance; 2013.

[31] IEC 60456. Clothes washing machines for household use - Methods for measuring the performance; 2010.

[32] JCGM 100. Evaluation of measurement data - Guide to the expression of uncertainty in measurement; 2008.

[33] Montgomery D.C. Design and analysis of experiments; John Wiley \& Sons: New York, 2005.

[34] MATLAB 2019a and Statistics and Machine Learning Toolbox 11.5; The MathWorks, Inc.: Natick, United States, 2019.

[35] Bajcar, T.; Blagojević, B.; Širok, B.; Dular, M. Influence of Flow Properties on a Structure of a Mineral Wool Primary Layer. Exp. Therm. Fluid Sci. 2007, 32, 440-449.

[36] Simoens, S.; Ayraul, M. Concentration Flux Measurements of a Scalar Quantity in Turbulent Flows. Exp. Fluids 1994, 16, 273-281.

[37] Aider, J.-L.; Westfreid, J.E. Visualizations and PDF of the Fluctuations of a Passive Scalar in a Turbulent Goertler Flow. Exp. Numer. Flow Visual. 1995, 218, 123-130.

[38] Bizjan, B.; Orbanić, A.; Širok, B.; Bajcar, T.; Novak, L.; Kovač, B. Flow Image Velocimetry Method Based on Advection-Diffusion Equation. Stroj. vestn. J. Mech. E. 2014, 60, 483-494.

[39] Bizjan, B.; Orbanić, A.; Širok, B.; Kovač, B.; Bajcar, T.; Kavkler, I. A Computer-Aided Visualization Method for Flow Analysis. Flow Meas. Instrum. 2014, 38, 1-8. 


\section{Table captions}

Table 1. Cotton test load composition [30,31] 


\section{Figure captions}

Figure 1: The experimental setup

Figure 2: Locations of sensors connected to the tumble dryer

Figure 3: (a) Computed velocity field, (b) average grayness level for selected time interval at $2 \mathrm{~kg}$ load, $36 \mathrm{rpm}$ drum speed and $400 \mathrm{~g}$ condensate mass

Figure 4: Drum outlet air relative humidity and condensate mass at constant drum speed of 36 rpm and different loads of 2 and $4 \mathrm{~kg}$; fabric concentration at approximately $30 \%, 60 \%$ and $90 \%$ relative condensate mass

Figure 5: Variation of space- and time-averaged values of $A$ as a function of relative condensate mass

Figure 6: Space- and time-averaged values of $A$ as a function of condensate mass flow rate Figure 7: Corrected energy efficiency for different load masses and drum speeds

Figure 8: Corrected drying time for different load masses and drum speeds

Figure 9: Measured vs. modeled condensate mass flow rate; (a) 4 and $6 \mathrm{~kg}$ load, (b) $2 \mathrm{~kg}$ load Figure 10: Modeled condensate mass flow rate for 4 and $6 \mathrm{~kg}$ load as a function of $m_{\mathrm{c}, \text { rel }}(\%)$ and $n(\mathrm{rpm})$

Figure 11: Modeled condensate mass flow rate for $2 \mathrm{~kg}$ load as a function of $m_{\mathrm{c}, \text { rel }}(\%)$ and $n$ (rpm); optimal $n$ with respect to $m_{\mathrm{c}, \text { rel }}$ (thick line)

Figure 12: Optimal drum speed for $2 \mathrm{~kg}$ load as a function of $m_{\mathrm{c}, \text { rel }}(\%)$ 


\begin{tabular}{|c|c|c|c|c|}
\hline & & Bed sheets & Pillowcases & Towels \\
\hline Mass per unit ar & $/ \mathrm{m} 2)$ & $185 \pm 10$ & & $220 \pm 10$ \\
\hline Length (mm) & & $2400 \pm 150$ & $800 \pm 50$ & $1000 \pm 50$ \\
\hline Width (mm) & & $1600 \pm 40$ & $800 \pm 20$ & $500 \pm 30$ \\
\hline Weight per piec & & $725 \pm 15$ & $240 \pm 5$ & $110 \pm 3$ \\
\hline Number of item & & & & \\
\hline & 2 & 0 & 4 & 9 \\
\hline Mass load (kg) & 4 & 2 & 4 & 14 \\
\hline & 6 & 2 & 8 & 24 \\
\hline
\end{tabular}



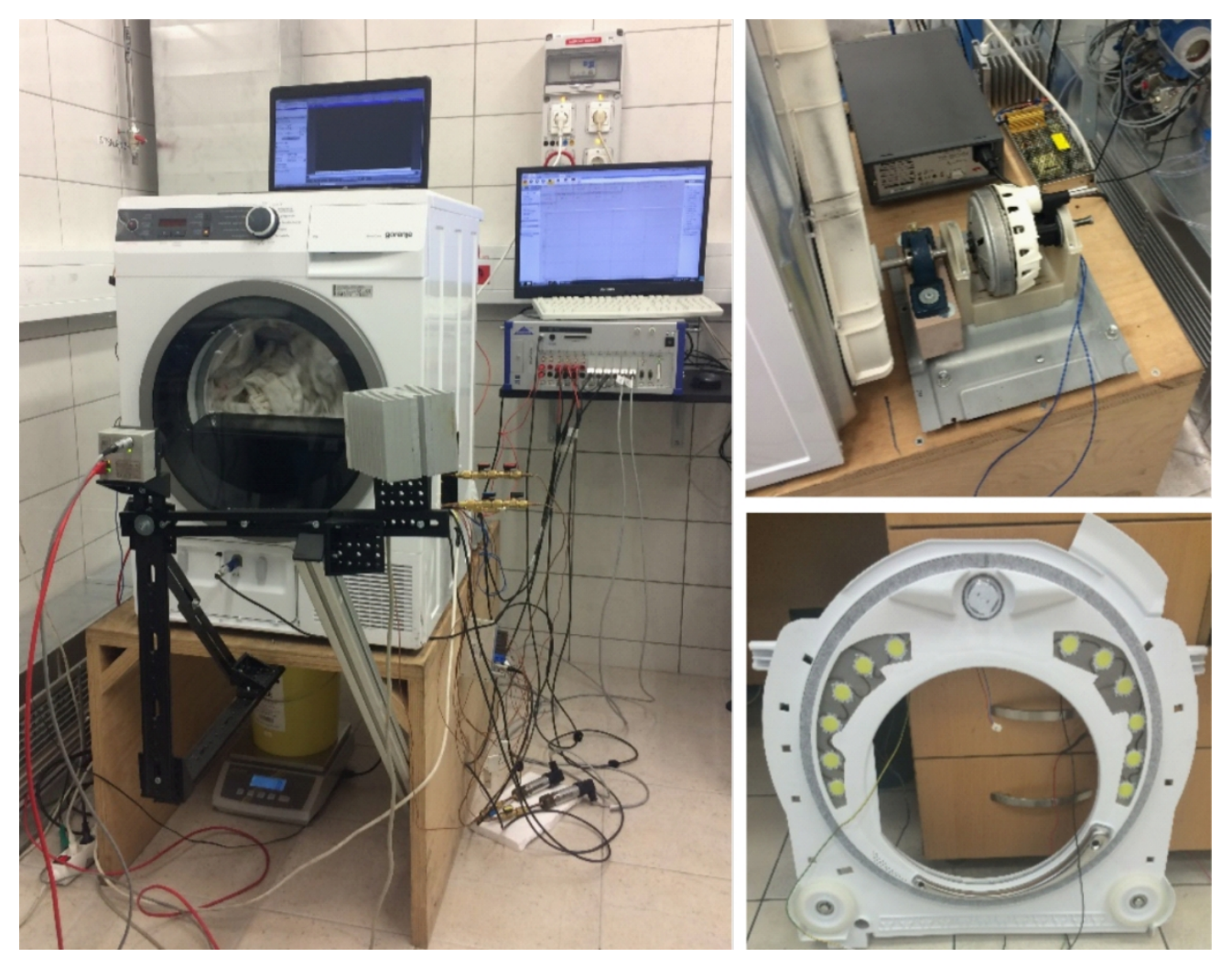

Figure 1: The experimental setup 




Figure 2: Locations of sensors connected to the tumble dryer 



Figure 3: (a) Computed velocity field, (b) average grayness level for selected time interval at $2 \mathrm{~kg}$ load, 36 rpm drum speed and $400 \mathrm{~g}$ of condensate 
Figure 4: Drum outlet air relative humidity and condensate mass at constant drum speed of $36 \mathrm{rpm}$ and different loads of 2 and $4 \mathrm{~kg}$; fabric concentration at approximately $30 \%, 60 \%$ and $90 \%$ relative condensate mass 


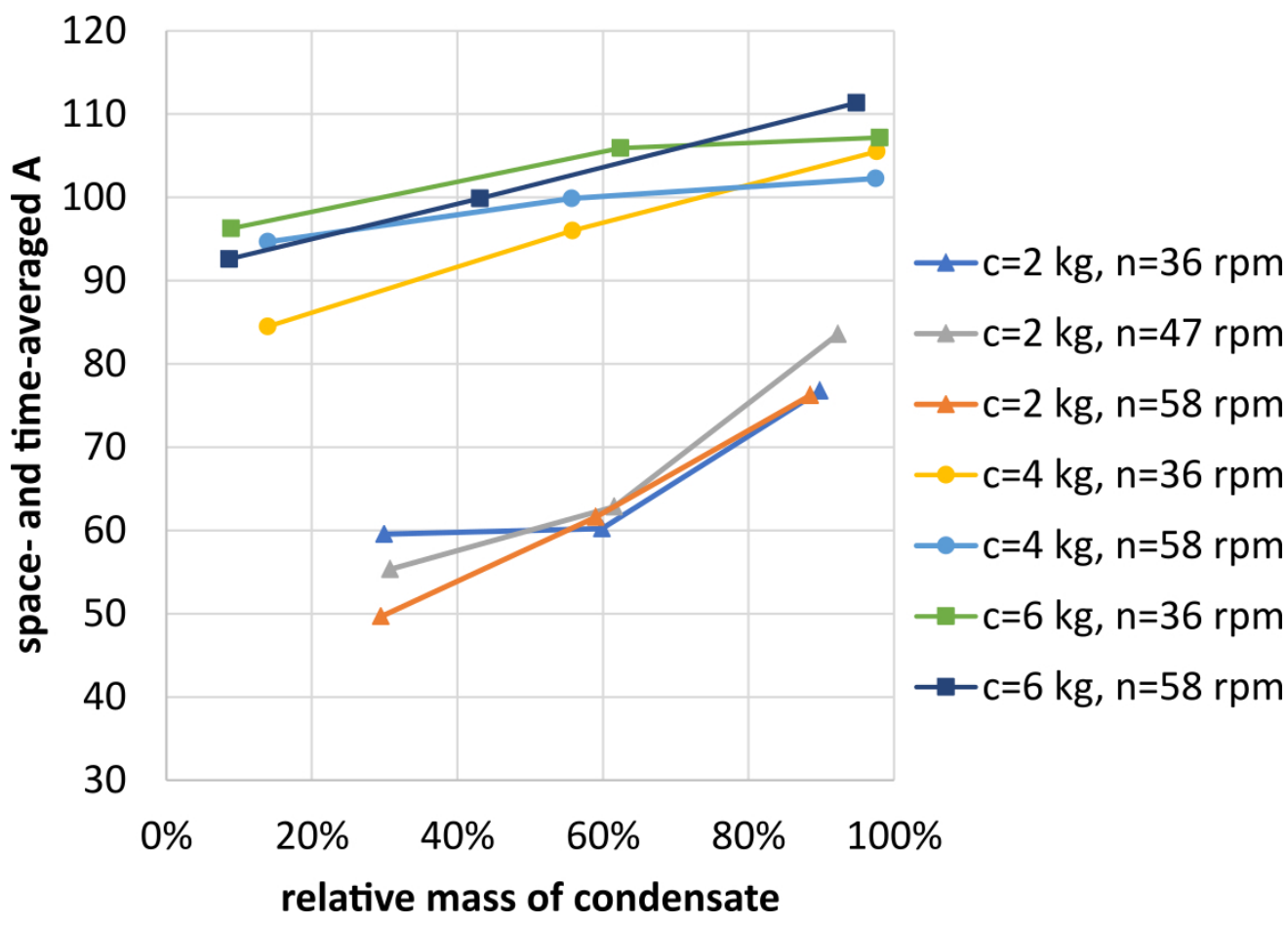

Figure 5: Variation of space- and time-averaged values of $A$ as a function of relative mass of condensate 


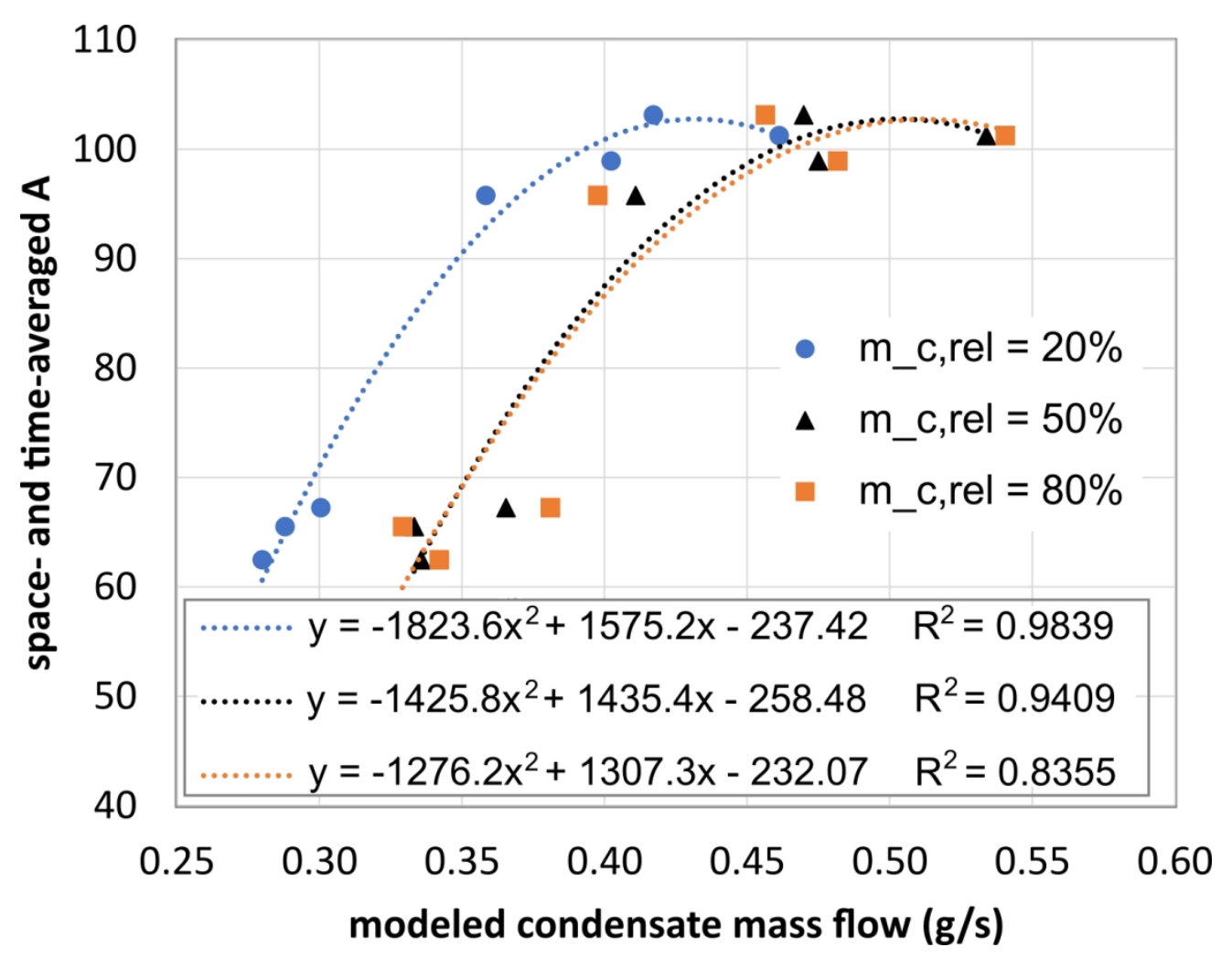

Figure 6: Space- and time-averaged values of $A$ as a function of condensate mass flow rate 


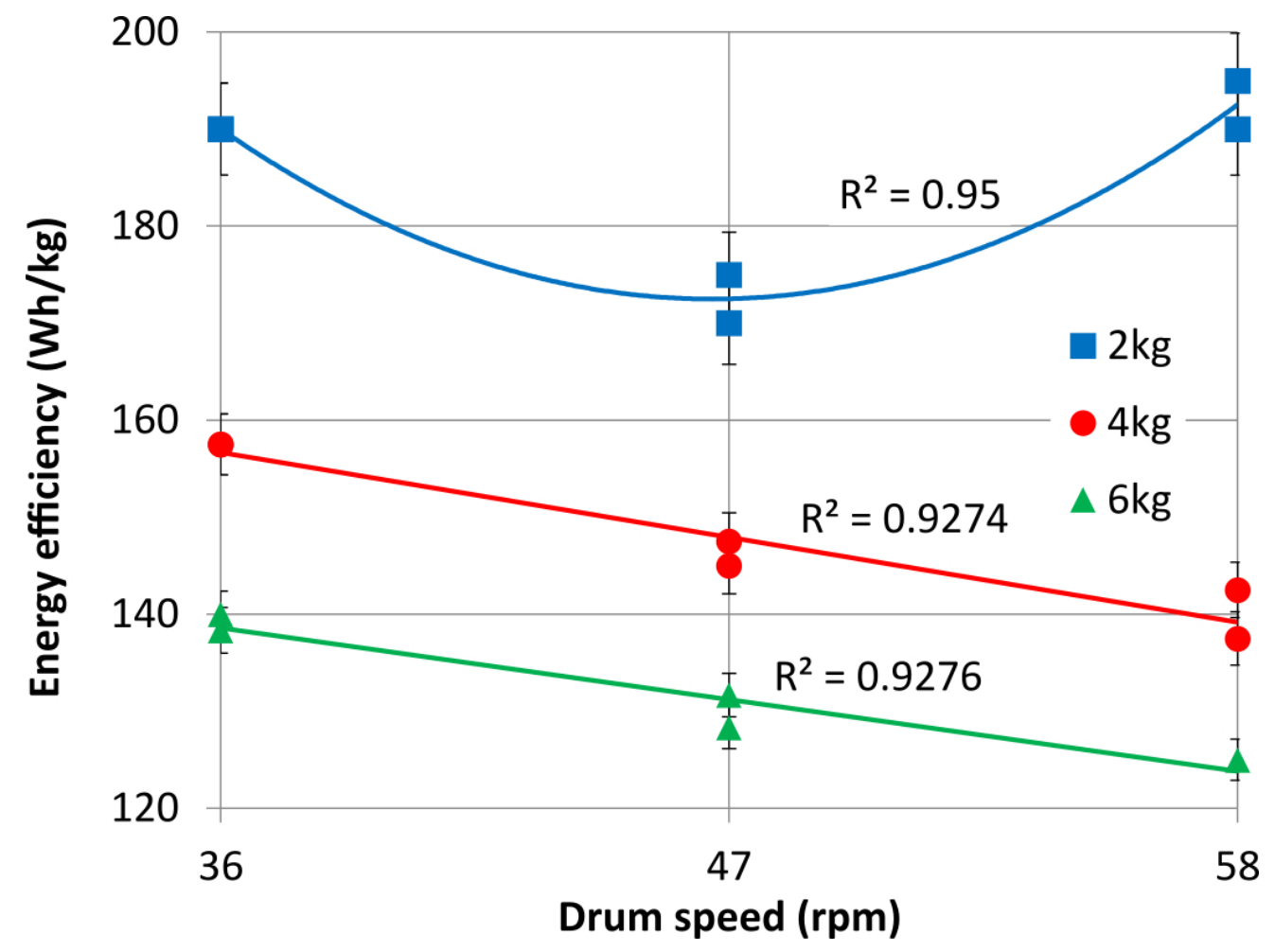

Figure 7: Corrected energy efficiency for different load masses and drum speeds 


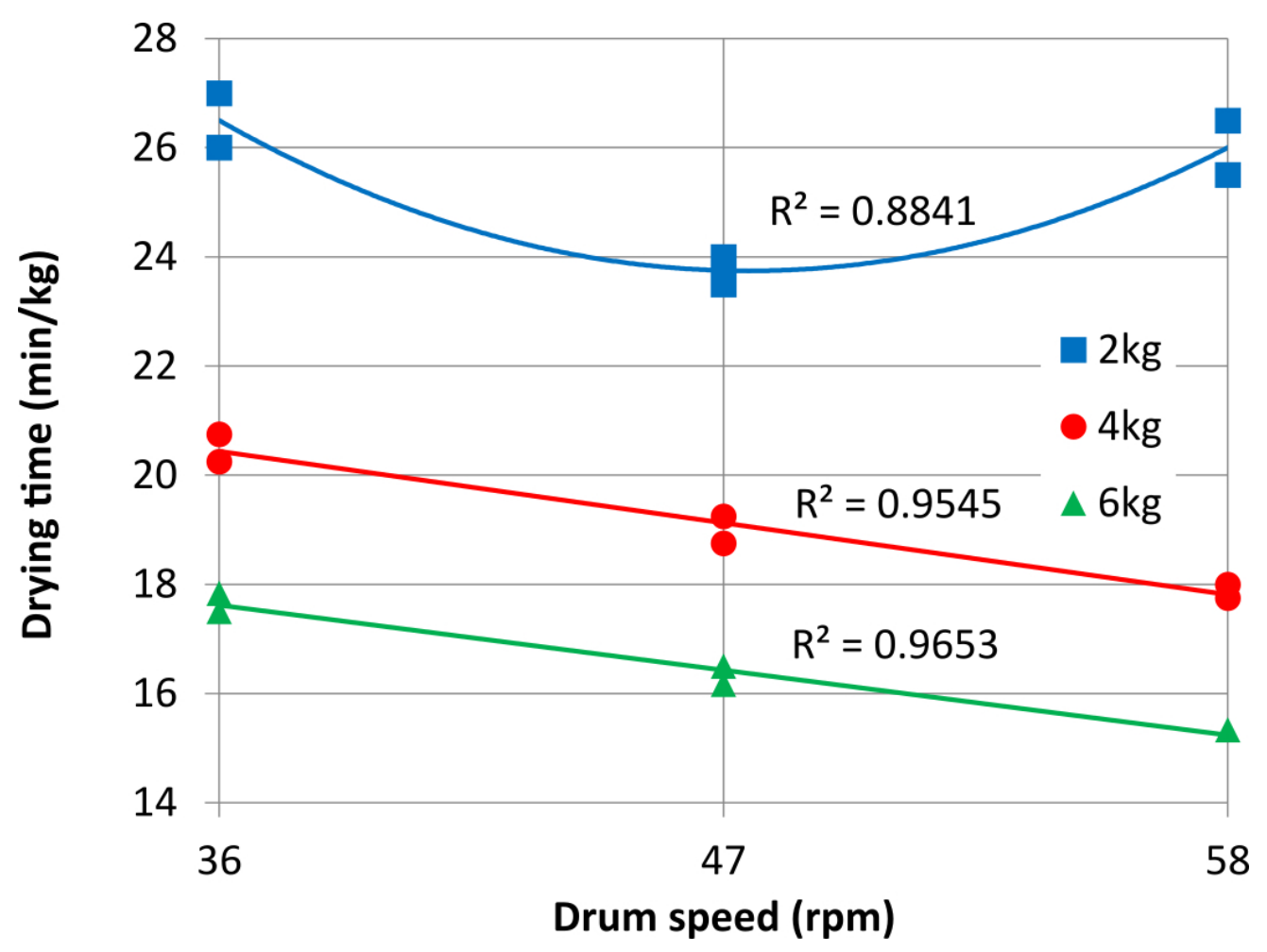

Figure 8: Corrected drying time for different load masses and drum speeds 

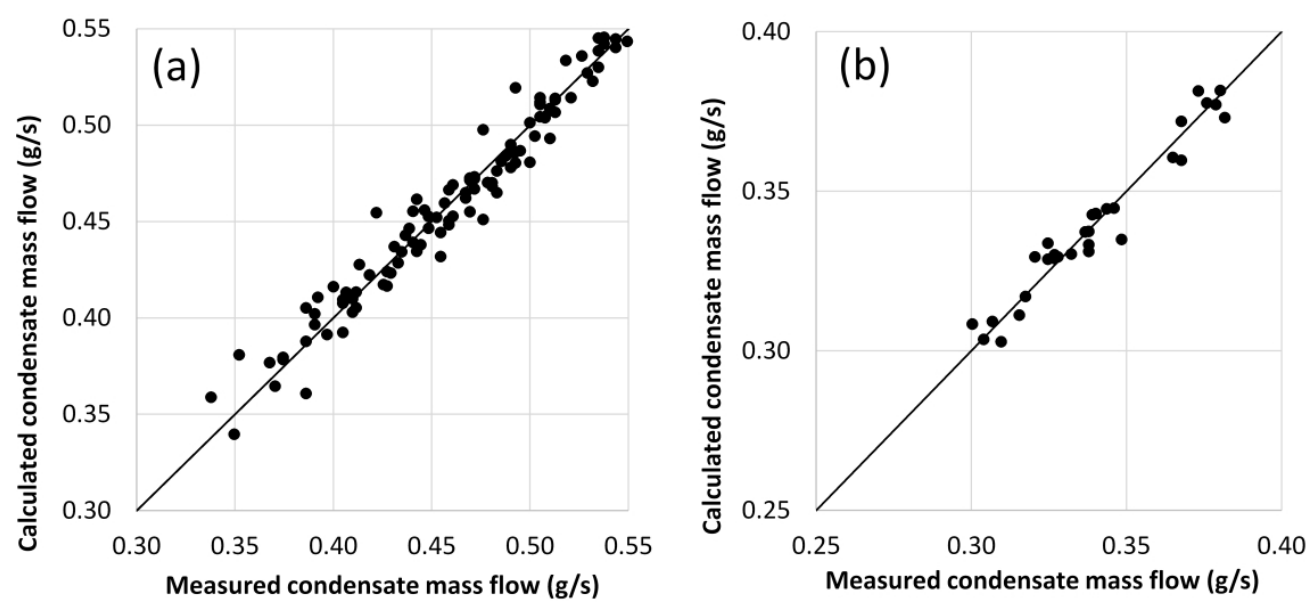

Figure 9: Measured vs. modeled condensate mass flow rate; (a) 4 and $6 \mathrm{~kg}$ load, (b) $2 \mathrm{~kg}$ load 


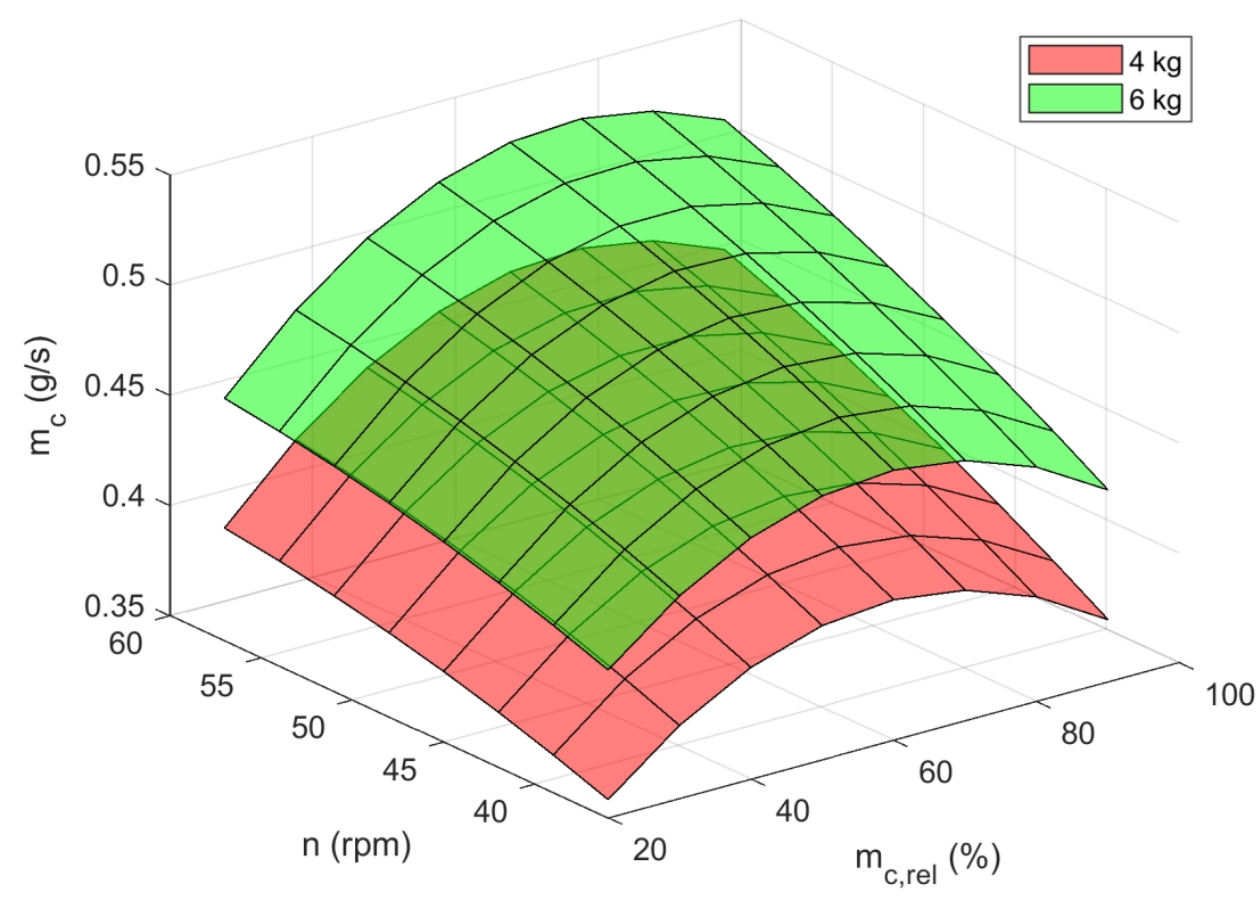

Figure 10: Modeled condensate mass flow rate for 4 and $6 \mathrm{~kg}$ load as a function of $m_{c, \text { rel }}(\%)$ and $n(\mathrm{rpm})$ 


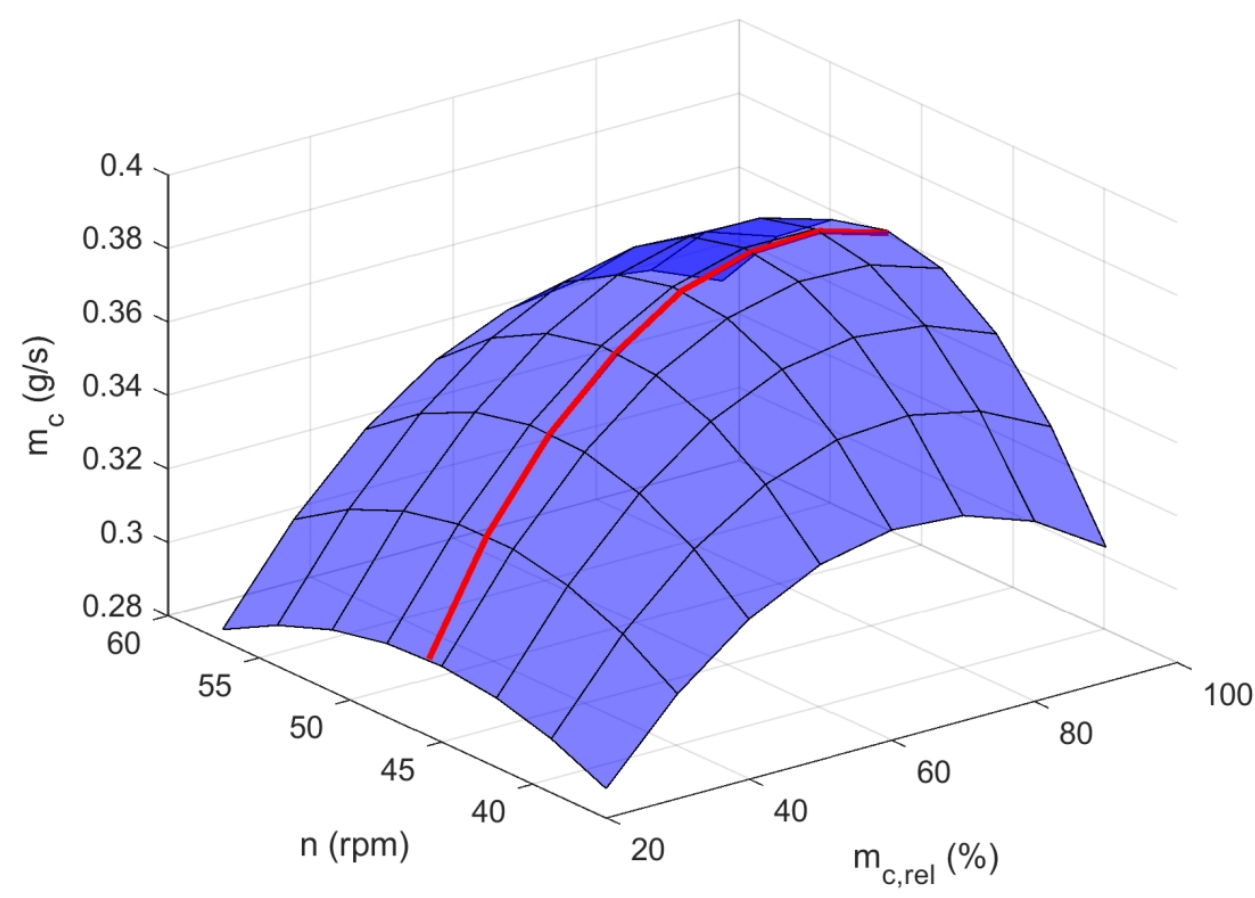

Figure 11: Modeled condensate mass flow rate for $2 \mathrm{~kg}$ load as a function of $m_{c, \text { rel }}(\%)$ and $n(\mathrm{rpm})$; optimal $\mathrm{n}$ with respect to $m_{c, \text { rel }}$ (thick line) 


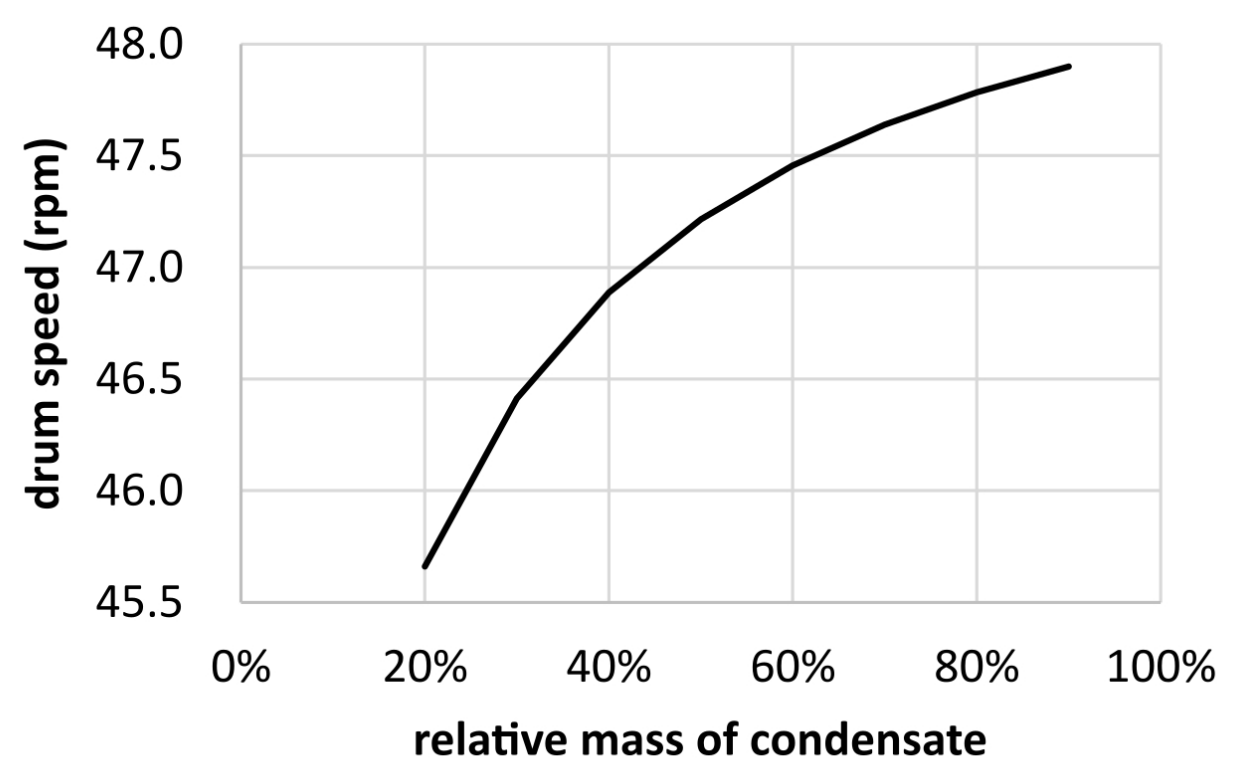

Figure 12: Optimal drum speed for $2 \mathrm{~kg}$ load as a function of $m_{c, \text { rel }}(\%)$ 